\title{
Anti-leishmanial and structure-activity relationship of ring substituted 3-phenyl-1-(1,4-di-N-oxide quinoxalin-2-yl)-2-propen-1-one derivatives
}

\author{
Asunción Burguete, Yannick Estevez ${ }^{1}{ }^{2}$, Denis Castilloº ${ }^{2}$ Germán González ${ }^{2}$, Raquel Villar, \\ Beatriz Solano, Esther Vicente, Silvia Pérez Silanes, Ignacio Aldana, Antonio Monge, \\ Michel Sauvain', Eric Deharo ${ }^{1 /+}$
}

Unidad de Investigación y Desarrollo de Medicamentos, Centro de Investigación en Farmacobiología Aplicada, University of Navarra, Campus Universitario, Pamplona, Spain 'UMR 152, Pharmacochimie des Substances Naturelles et Pharmacophores Redox, IRD -

Université Toulouse III ' ${ }^{2}$ Laboratorios de Investigación y Desarrollo, Facultad de Ciencias y Filosofía, Universidad Peruana Cayetano Heredia (UPCH), Av. Honorio Delgado 430, SMP, Lima, Perú

A series of ring substituted 3-phenyl-1-(1,4-di-N-oxide quinoxalin-2-yl)-2-propen-1-one derivatives were synthesized and tested for in vitro leishmanicidal activity against amastigotes of Leishmania amazonensis in axenical cultures and murine infected macrophages. Structure-activity relationships demonstrated the importance of a radical methoxy at position $R_{3}{ }^{\prime}, R_{4}{ }^{\prime}$ and $R_{5}{ }^{\prime}$. (2E)-3-(3,4,5-trimethoxy-phenyl)-1-(3,6,7-trimethyl-1,4-dioxy-quinoxalin2-yl)-propenone was the most active. Cytotoxicity on macrophages revealed that this product was almost six times more active than toxic.

Key words: quinoxaline - anti-leishmanial - structure-activity - Leishmaniasis

Leishmaniasis is a tropical parasitosis caused by Trypanosomatidae of the Leishmania genus extended over Africa, Asia, Europe, North and South America, with an estimated 12 million people infected worldwide. Clinically, leishmaniasis occurs in visceral, cutaneous and mucocutaneous forms. Chemotherapy is restricted to pentavalent antimonials, amphotericin B and pentamidine, which require parenteral administration, are toxic, expensive and have restricted therapeutic spectrums in different clinical forms of leishmaniasis (Davis et al. 2004). Recently, miltefosine has been shown to be active by oral treatment against Bolivian mucosal leishmaniasis (Soto et al. 2007); however, this treatment is not very effective against other types of leishmaniasis (Yardley et al. 2005). In this context, the discovery of new active and promising compounds with anti-leishmanial potential remains essential for the control and prevention of leishmaniasis. Quinoxaline derivatives have been reported to have anti-protozoal activity against malaria parasites (Rangisetty et al. 2001, Zarranz et al. 2005, Marin et al. 2007) and also against promastigote forms of Leishmania amazonensis and Leishmania infantum (Guillon et al. 2007). In our efforts to identify new anti-leishmanial

Yannick Estevez and Denis Castillo contributed equally to this work Financial support: A Burguete was awarded a PhD fellowship supported by the "Gobierno de Navarra"; D Castillo was supported by the Belgian Technical Cooperation of Lima, Peru.

+ Corresponding autor: ericdeharo@gmail.com

Received 10 June 2008

Accepted 31 October 2008 drug candidates, we describe herein the relationship between structure and anti-leishmanial activity of new quinoxaline 1,4-di- $N$-oxide derivatives on amastigotes of L. amazonensis (strain MHOM/BR/76/LTB-012).

\section{MATERIALS AND METHODS}

Chemicals and instruments - Alugram ${ }^{\circledR}$ SIL G/ UV254 (Layer: $0.2 \mathrm{~mm}$ ) (Macherey-Nagel GmbH \& Co, KG, Postfach 101352. D-52313 Düren, Germany) was used for Thin Layer Chromatography and Silica gel $60(0.040-0.063 \mathrm{~mm})$ for Column flash Chromatography (Merck). All reagents and solvents were purchased from: Merck (Darmstadt, Germany), Scharlau (FEROSA, Barcelona, Spain), Panreac Química SA (Montcada i Reixac, Barcelona, Spain), Sigma-Aldrich Química SA, (Alcobendas, Madrid), Acros Organics (Janssen Pharmaceuticalaan 3a, 2440 Geel, België) and Lancaster (Bischheim-Strasbourg, France).

Compounds $2 \mathrm{a}-\mathrm{e}, 3 \mathrm{a}-\mathrm{f}, 4 \mathrm{~b}$ and $4 \mathrm{~d}$ (Table) were synthesized according to Burguete et al. (2007). Melting points were determined with a Mettler FP82+FP80 apparatus (Greifense, Switzerland) and have not been corrected. The ${ }^{1} \mathrm{H}$ NMR spectra were recorded on a Bruker 400 Ultrashield $^{\mathrm{TM}}$ (Bruker BioSpin GmbH, Rheinstetten, Germany), using TMS as the internal standard and with $\mathrm{CDCl}_{3}$ and DMSO- $d_{6}$ as the solvents.

Distribution coefficient $(\log P)$ - LogP was calculated with the online software Pharma-algorithms (available from: http://pharma-algorithms.com/). $\log \mathrm{P}$ is a measure of a drug's lipophilicity and an indication of its ability to cross cell membranes (Scherrer \& Howard 1977). Drugs having values of $p$ beyond 1 are classified as lipophilic, whereas those with partition coefficients smaller than 1 are indicative of hydrophilic drugs. This can be calculated in silico or by using an HPLC method (Valkó 2004); the higher the value, the more lipophilic the drug. 
TABLE

Antileishmanial activity on axenic amastigotes and infection rates of L. amazonensis and LogP calculated in silico (http://pharma-algorithms.com/) of the tested compounds

\begin{tabular}{|c|c|c|c|c|c|c|c|c|c|}
\hline Drugs & R6 & $\mathrm{R} 7$ & $\mathrm{R}_{3}{ }^{\prime}$ & $\mathrm{R}_{4}{ }^{\prime}$ & $\mathrm{R}_{5}{ }^{\prime}$ & $\mathrm{IC}_{50}$ & SI & $\mathrm{IC}_{50}(\mathrm{IR})$ & $\log P$ \\
\hline $2 \mathrm{a}$ & $\mathrm{H}$ & $\mathrm{H}$ & $\mathrm{OCH}_{3}$ & $\mathrm{OCH}_{3}$ & $\mathrm{OCH}_{3}$ & $4,9 \pm 2.1$ & 2,8 & 13,1 & 0.85 \\
\hline $2 b$ & $\mathrm{H}$ & $\mathrm{OCH}_{3}$ & $\mathrm{OCH}_{3}$ & $\mathrm{OCH}_{3}$ & $\mathrm{OCH}_{3}$ & $65,6 \pm 22.9$ & 1,2 & 23,5 & 0.8 \\
\hline $2 \mathrm{c}$ & $\mathrm{H}$ & $\mathrm{Cl}$ & $\mathrm{OCH}_{3}$ & $\mathrm{OCH}_{3}$ & $\mathrm{OCH}_{3}$ & $37,0 \pm 7.8$ & 4,3 & 23,2 & 1.23 \\
\hline $2 d$ & $\mathrm{H}$ & $\mathrm{F}$ & $\mathrm{OCH}_{3}$ & $\mathrm{OCH}_{3}$ & $\mathrm{OCH}_{3}$ & $2,7 \pm 0.6$ & 5,1 & 24,1 & 0.73 \\
\hline $2 \mathrm{e}$ & $\mathrm{CH}_{3}$ & $\mathrm{CH}_{3}$ & $\mathrm{OCH}_{3}$ & $\mathrm{OCH}_{3}$ & $\mathrm{OCH}_{3}$ & $4,1 \pm 0.5$ & $>5,7$ & 17,7 & 1.67 \\
\hline $3 a$ & $\mathrm{H}^{3}$ & $\mathrm{H}^{3}$ & $\mathrm{O}-\mathrm{C}$ & $2-\mathrm{O}$ & $\mathrm{H}^{3}$ & $>100$ & NT & - & 1.49 \\
\hline $3 b$ & $\mathrm{H}$ & $\mathrm{OCH}_{3}$ & $\mathrm{O}-\mathrm{C}$ & $-\mathrm{O}$ & $\mathrm{H}$ & $>100$ & NT & - & 1.44 \\
\hline $3 \mathrm{c}$ & $\mathrm{H}$ & $\mathrm{Cl}$ & $\mathrm{O}-\mathrm{C}$ & $-\mathrm{O}$ & $\mathrm{H}$ & $>100$ & NT & - & 1.87 \\
\hline $3 d$ & $\mathrm{H}$ & $\mathrm{F}$ & $\mathrm{O}-\mathrm{C}$ & $-\mathrm{O}$ & $\mathrm{H}$ & $>100$ & NT & - & 1.37 \\
\hline $3 e$ & $\mathrm{CH}_{3}$ & $\mathrm{CH}_{3}$ & $\mathrm{O}-\mathrm{C}$ & $2-\mathrm{O}$ & $\mathrm{H}$ & $>100$ & NT & - & 2.31 \\
\hline $3 f$ & $\mathrm{H}$ & $\mathrm{CH}_{3}$ & $\mathrm{O}-\mathrm{C}$ & $2-\mathrm{O}$ & $\mathrm{H}$ & $>100$ & NT & - & 1.9 \\
\hline $4 b$ & $\mathrm{H}$ & $\mathrm{OCH}_{3}$ & $\mathrm{OCH}$ & $\mathrm{OH}$ & $\mathrm{H}$ & $5,3 \pm 2.3$ & 25,2 & 43,7 & 0.59 \\
\hline $4 d$ & $\mathrm{H}$ & $F^{3}$ & $\mathrm{OCH}$ & $\mathrm{OH}$ & $\mathrm{H}$ & $6,7 \pm 1.3$ & 20,7 & 42,9 & 0.53 \\
\hline Amph.B & & & & & & $0.06 \pm 0.01$ & 73 & 0.6 & - \\
\hline
\end{tabular}

$\mathrm{IC}_{50}$ : concentration inhibiting $50 \%$ of the parasite growth, in $\mu \mathrm{M}$; IR: infection rate; NT: not tested; SI: Selectivity Index $\left(\mathrm{TD}_{50} / \mathrm{IC}_{50}\right)$.

Activity of quinoxaline derivatives on axenic amastigotes - Axenically grown amastigotes of L. amazonensis (strain MHOM/BR/76/LTB-012) were maintained by weekly sub-passages in medium for axenically grown amastigotes (extensively described by Sereno \& Lemesre 1997a) and supplemented with $20 \%$ of foetal bovine serum at $32^{\circ} \mathrm{C}$ with $5 \% \mathrm{CO}_{2}$ in $25 \mathrm{~cm}^{2}$ tissue culture flasks. Cultures were initiated with $10^{6}$ amastigotes $/ \mathrm{mL}$ in $25 \mathrm{~cm}^{2}$ tissue culture flasks with $5 \mathrm{~mL}$ of media. In order to determine the activity of the drugs, the 3-(4,5-dimethylthiazol-2yl)-2,5-diphenyltetrazolium bromide (MTT) micromethod was used as previously described by Sereno and Lemesre (1997b). Briefly, $100 \mu \mathrm{L}$ of axenically grown amastigotes, from late LogPhase of growth, were seeded in 96-well flat bottom microtiter plates. The drugs, dissolved in dimethylsulfoxide (DMSO), were added at final concentrations ranging from 100 to $1 \mu \mathrm{g} / \mathrm{mL}$. All experiments were performed in triplicate. The final DMSO concentration was never greater than $0.1 \%$. After $72 \mathrm{~h}$ of incubation, $10 \mu \mathrm{L}$ of MTT $(10 \mathrm{mg} / \mathrm{mL})$ was added to each well and plates were further incubated for $4 \mathrm{~h}$. The enzymatic reaction was then stopped with $100 \mu \mathrm{L}$ of $50 \%$ isopropanol (v/v) -10\% sodium dodecyl sulphate (w/v) and incubated for an additional $30 \mathrm{~min}$, under agitation, at rt. Finally, the optical density was read at $590 \mathrm{~nm}$ with a 96-well scanner (Bio-Rad).

The percentage of growth inhibition of the parasite was calculated by the following formula:

$$
\frac{(\text { OD control - OD drugs) } \times 100=\% \text { of inhibition }}{\text { OD control }}
$$

The dose inhibiting $50 \%$ of the parasite growth $\left(\mathrm{IC}_{50}\right)$ was calculated (Excel software).
Reference compounds were amphotericin B and gluconate antimoniate of meglumine (Glucantime).

Activity on infected macrophages - Macrophages were harvested from peritoneal cavities of 6-8 week-old female BALB/c mice in ice-cold M199 medium (supplemented with $10 \%$ foetal bovine serum), adapted from Sauvain et al. (1993). The cells were plated at $10 \% \mathrm{~mL}$ on glass coverslips and incubated at $37^{\circ} \mathrm{C}$ under an atmosphere of $5 \% \mathrm{CO}_{2}$ for $24 \mathrm{~h}$. Non-adherent cells were removed by washing with pre-warmed M199 medium. Medium was then replaced by a suspension of amastigotes, using an infection ratio of 3/1 amastigotes/macrophages, for $2 \mathrm{~h}$ at $32^{\circ} \mathrm{C}$ in $5 \% \mathrm{CO}_{2}$. Calls were then washed three times with pre-warmed M199 medium to remove free parasites. The drug to be tested, dissolved in DMSO, was then added and incubated for $48 \mathrm{~h}$ at $37^{\circ} \mathrm{C}$ in $5 \% \mathrm{CO}_{2}$. Cultures were subsequently fixed with absolute methanol, stained with Giemsa and examined by light microscopy. The number of intracellular amastigotes was determined by counting amastigotes in 300 macrophages. All experiments were performed in triplicate.

The infection rates (IR) were calculated according to Delorenzi et al. (2001) and Monzote et al. (2004). Then, the drug concentration able to reduce the IR in macrophages by $50 \%, \mathrm{IC}_{50}$ (IR), was calculated using the PROBIT formula in Excel.

Cytotoxicity on macrophages - Murine macrophages were treated with the drug and their viabilities were determined by trypan blue dye exclusion. Living cells exclude the dye, whereas dead cells take up the blue dye. Resident mouse macrophages adhering to 96 -well plates 
were incubated for $24 \mathrm{~h}$ at $37^{\circ} \mathrm{C}$ in $5 \% \mathrm{CO}_{2}$. Drugs were then added and cells returned to culture for $48 \mathrm{~h}$. Finally, macrophages were incubated with $0.4 \%$ trypan blue solution and the viable cells were enumerated with a microscope. One hundred cells were counted for each concentration and the number of viable cells that excluded trypan blue was determined to calculate percentage of viability. The drug dose killing $50 \%$ of the macrophages $\left(\mathrm{TD}_{50}\right)$ was then determined with the PROBIT formula of Excel software. Amphotericin B was used as a control.

\section{RESULTS AND DISCUSSION}

Anti-leishmanial activities of the studied compounds are listed in Table. Compounds 3a-f were inactive against axenic amastigotes with an $\mathrm{IC}_{50}>100 \mu \mathrm{M}$. Compounds in series 2 and 4 presented the best anti-leishmanial activities, displaying $\mathrm{IC}_{50}$ ranging from 2.8 to $65.6 \mu \mathrm{M}$. We can therefore say that when the hydroxy and methoxy groups are substituted by a methylenedioxy group, the activity decreases dramatically. Moreover, product $2 \mathrm{~d}$ with a fluorine atom in R7 was the most active against axenic amastigotes with an $\mathrm{IC}_{50}$ at around $3 \mu \mathrm{M}$. The active compounds (series: 2 and 4) were then evaluated on non-infected macrophages to determinate their selectivity index. Products $4 \mathrm{~b}$ and $4 \mathrm{~d}$ were the most selective, followed by $2 \mathrm{e}, 2 \mathrm{~d}$ and $2 \mathrm{c}$; products $2 \mathrm{a}$ and $2 \mathrm{~b}$ were the least selective. Amphotericin $\mathrm{B}$ was also tested against non-infected macrophages and was shown to be around 70 times less cytotoxic on macrophages than on axenic amastigotes.

In order to gain further insight into the ability of these drugs to cross cell membranes, $\log \mathrm{P}$ values were calculated by computational analysis with using the help of Pharma-algorithms (available from http:// pharma-algorithms.com) in silico. Compound 2e was shown to be the most lipophilic among the most active compounds. Interestingly, apart from $2 \mathrm{e}$, the active compounds against axenic amastigotes had $\log \mathrm{P}$ values $<1.25$, while inactive drugs showed $\log P$ values $>1.25$. These results are in agreement with previously published results by Valderama et al. (2005) showing that the lipophilicity of leishmanicidal quinones is correlated with their leishmanicidal activity. Compounds $4 \mathrm{~b}$ and $4 \mathrm{~d}$, with a hydroxyl group in the structure, were less active $\left(\mathrm{IC}_{50}(\mathrm{IR})>40 \mu \mathrm{M}\right)$ against $L$. amazonensis infected macrophages than compounds in group 2, with three methoxy groups. Interestingly, $2 \mathrm{~b}, 2 \mathrm{c}$ and $2 \mathrm{~d}$ have similar $\mathrm{IC}_{50}$ (IR) $(>20 \mu \mathrm{M})$, while $2 \mathrm{a}$ and $2 \mathrm{e}$ have the lowest IC $_{50}$ (IR) (around $13.1 \mu \mathrm{M}$ and $17.7 \mu \mathrm{M}$ respectively); with compound $2 \mathrm{e}$ showing less cytotoxicity than $2 \mathrm{a}$.

Thus, our results suggest that compound $2 \mathrm{e},(2 \mathrm{E})-3$ (3,4,5-trimethoxy-phenyl)-1-(3,6,7-trimethyl-1,4-dioxyquinoxalin-2-yl)-propenone, should be considered for further in vivo studies against Leishmania parasites.

\section{ACKNOWLEDGMENTS}

To Colleen McClean and Claudia Landini, for the critical reading of the manuscript.

\section{REFERENCES}

Burguete A, Pontiki E, Hadjipavlou-Litina D, Villar R, Vicente E, Solano B, Ancizu S, Pérez-Silanes S, Aldana I, Monge A 2007. Syn- thesis and anti-inflammatory/antioxidant activities of some new ring substituted 3-phenyl-1-(1,4-di- $N$-oxide quinoxalin-2-yl)-2propen-1-one derivatives and of their 4,5-dihydro-( $1 H)$-pyrazole analogues. Bioorg Med Chem Lett 17: 6439-6443.

Davis AJ, Murray HW, Handman E 2004. Drugs against leishmaniasis: a synergy of technology and partnerships. Trends in Parasitol 20: $73-76$.

Delorenzi JC, Attias M, Gattass CR, Andrade M, Rezende C, Pinto AC, Henriques AT, Bou-Habib DC, Saraiva E 2001. Antileishmanial activity of an indole alkaloid from Peschiera australis. Antimicrob Agents Chemother 45: 1349-1354.

Guillon J, Forfar I, Mamani-Matsuda M, Desplat V, Saliege M, Thiolat D, Massip S, Tabourier A, Leger JM, Dufaure B, Haumont G, Jarry C, Mossalayi D 2007. Synthesis, analytical behaviour and biological evaluation of new 4-substituted pyrrolo[1,2-a]quinoxalines as antileishmanial agents. Bioorg Med Chem 15: 194-210.

Marin A, Moreira Lima L, Solano B, Vicente E, Pérez Silanes S, Maurel S, Sauvain M, Aldana I, Monge A, Deharo E 2007. Antiplasmodial structure-activity relationship of 3-trifluoromethyl-2-arylcarbonylquinoxaline 1,4-di-N-oxide derivatives. Exp Parasitol 118: 25-31.

Monzote Fidalgo L, Montalvo Alvarez AM, Geigel LF, Pérez Pineiro R, Suárez Navarro M, Rodríguez Cabrera H 2004. Effect of thiadiazine derivatives on intracellular amastigotes of Leishmania amazonensis. Mem Inst Oswaldo Cruz 99: 329-330.

Rangisetty JB, Gupta CNVHB, Prasad AL, Srinivas P, Sridhar N, Parimoo P, Veeranjaneyulu A 2001. Synthesis of new arylaminoquinoxalines and their antimalarial activity in mice. $J$ Pharm Pharmacol 53: 1409-1413.

Sauvain M, Dedet JP, Kunesch N, Poisson J, Gayral P, Gantier JC, Kunesch G 1993. In vitro and in vivo leishmanicidal activities of natural and synthethic quinoids. Phytother Res 7: 167-171.

Scherrer RA, Howard SM 1977. Use of distribution coefficients in quantitative structure-activity relationships. J Med Chem 20: 53-58.

Sereno D, Lemesre JL 1997a. Axenically cultured amastigote forms as an in vitro model for investigation of antileishmanial agents. Antimicrob Agents Chemother 41: 972-976.

Sereno D, Lemesre JL 1997b. Use of an enzymatic micromethod to quantity amastigotes stage of Leishmania amazonensis in vitro. Parasitol Res 83: 401-403.

Soto J, Toledo J, Valda L, Balderrama M, Rea I, Parra R, Ardiles J, Soto P, Gomez A, Molleda F, Fuentelsaz C, Anders G, Sindermann H, Engel J, Berman J 2007. Treatment of Bolivian mucosal leishmaniasis with miltefosine clinical infectious diseases. Clin Infect Dis 44: 350-356.

Valderrama JA, Zamorano C, González MF, Prina E, Fournet A 2005. Studies on quinones. Part 39: Synthesis and leishmanicidal activity of acylchloroquinones and hydroquinones. Bioorg Med Chem 1: 4153-4159.

Valkó K 2004. Application of high-performance liquid chromatography based measurements of lipophilicity to model biological distribution. J Chromatogr 1037: 299-310.

Yardley V, Croft SL, de Doncker S, Dujardin JC, Koirala S, Rijal S, Miranda C, Llanos-Cuentas A, Chappuis F 2005. The sensitivity of clinical isolates of Leishmania from Peru and Nepal to miltefosine. Am J Trop Med Hyg 73: 272-275.

Zarranz B, Jaso A, Aldana I, Monge A, Maurel S, Deharo E, Jullian V, Sauvain M 2005. Synthesis and antimalarial activity of new 3-arylquinoxaline-2-carbonitrile derivatives. Arzneimittelforschung 55: 754-761. 